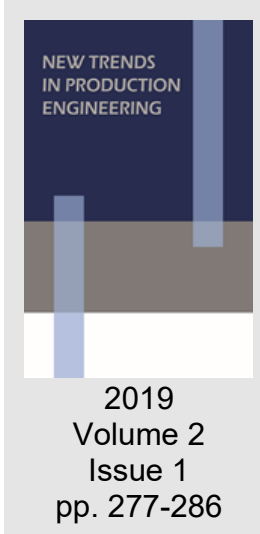

\title{
Directions for increasing conical picks' durability
}

\author{
Łukasz Bołoz \\ AGH University of Science and Technology, Poland
}

Volume 2

p. $277-286$

Date of submission to the Editor: 05/2019

Date of acceptance by the Editor: 07/2019

\section{INTRODUCTION}

Conical picks are more and more frequently applied in the milling heads of mining machines. In the case of difficult conditions and mining in hard rocks, their durability is considerably limited. This translates into reduced efficiency of mining and increased costs. Replacement of conical picks, which may be necessary even after a few hours of work, is particularly problematic. It should be noted that their number on the cutting head usually ranges from approximately 40 to 60 pieces, so this issue has a clear practical and economic aspect. Milling heads are applied as mining elements of many machines in underground and open-pit mining as well as in the construction and road building branch.

Conical picks are the subject of investigations and development works in many research centres all over the world. These studies are mainly aimed at finding a solution characterized by the highest resistance to abrasive wear. Some research was done on picks in which the body was protected against abrasive wear by means of abrasion resistant coatings, hardfacing or sintered carbide rings (Chang and Chulho, 2017, Krauze et al., 2016). Studies were carried out to get to know the mechanism of pick abrasion wear (Dewangan and Chattopadhyaya, 2015), wear prediction (Gajewski et al., 2013) or the possibility to support the mining process (Kotwica, 2011) or granulation (Sidor and Feliks, 2015). Sintered carbide (Nahak et al., 2015) and steel (Gajdzik and Sitko, 2014, 2016) as well as a complete pick (Songyong et al., 2017) or picks in the cutting head (Krauze et al., 2015, Krauze and Kotwica, 2007) were subjected to tests. Also implementation works with the aim to apply modern tools and machines in difficult conditions (Bołoz and Krauze, 2018, Krauze and Bołoz, 2018) and to apply alternative tools in the form of discs (Gospodarczyk et al., 2013, 2016, Kotwica, 2018, Romanyshyn et al., 2017) were carried out. The subject of studies were also procedures for evaluating the quality of picks enabling the user to choose the best offer in public tenders (Bołoz, 2018). 


\section{CONICAL PICKS}

A standard conical pick has the shape of a solid of revolution, consisting of a working part, a one- or two-stage cylindrical mandrel, which is a part of the pick holder, and a tip in the form of a sintered carbide insert (Fig. 1a). Conical picks of mining heads are equipped with bearings placed directly in pick holders or in sleeves being an integral part of the holder, or in sleeves that constitute an additional element between the holder and the pick. The shape of picks and the manner of their mounting in the holder result from the necessity to ensure their free rotation in relation to the axis of symmetry, which results in a uniform wear of the tip. The uniform wear of the pick and simultaneous shortening of its working part enable correct cutting angles to be maintained. The body with the holder constitute one element made of steel characterized by appropriate impact resistance $\left(U_{\min } \approx 25 \mathrm{~J} / \mathrm{cm}^{2}\right)$, tensile strength $\left(R_{\mathrm{m} \min } \approx 1000 \mathrm{MPa}\right)$ and abrasive resistance. It is recommended that the hardness of the working part of the body measured by the Rockwell method reach at least 45 HRC, whereas the shank's hardness, due to the risk of damaging the holders, should be within a range of $30 \mathrm{HRC} \pm 5 \mathrm{HRC}$. Depending on the intended use of the tools, they are made of steel in grades $12 \mathrm{HN} 3 \mathrm{~A}, 40 \mathrm{H}, 40 \mathrm{HN}, 36 \mathrm{HNM}$ or $35 \mathrm{HGS}$, which is additionally subjected to the process of thermal and chemical treatment in order to improve the top layer's abrasive resistance. Alternatively, the abrasion resistant layers are made of stellites or sintered carbides based on cobalt, nickel or iron, which are applied in the process of plasma or laser hard facing, or by TIG or micro TIG methods. Hard facing involves using electrodes in the form of powders, rods or tubes with powders. The hardness of coatings can reach a level of even $60 \mathrm{HRC}$. The tip is made of various types of sintered carbides characterized by high hardness, which should reach minimum $\mathrm{HV}_{30}$ min $\approx 1050$ by the Vickers method. Irrespective of the grade, typical mining sintered carbides belonging to group $B$ in $89 \% \div 93 \%$ consist of hard, abrasion resistant tungsten carbide, whereas the remaining part is made up of cobalt $\mathrm{C}$, being a binding phase. Sintered carbide is brazed to the seat in the working part of the pick's body. Materials that are usually used to equip conical picks include carbides B2, B20, B23, G15 as well as other materials with a similar chemical composition and properties. For research purposes, the picks' bodies are also made of ceramic materials or modern casts. Abrasion resistant layers subjected to testing are made of materials applied in mechanical engineering for abrasion resistant coatings, such as titanium nitride.

The durability of tools is mainly influenced by their appropriate selection, suited to the predicted mining and geological conditions, in particular the physical properties of the face. Important parameters having an impact on the proper course of the milling process include geometrical and kinematic parameters of the pick in the holder and of the cutting head in the mining machine. Based on the analysis of available conical picks, mainly of longwall shearers and road headers, a comparison of their parameters was prepared (Fig. 1b):

- total length of pick: $L_{c}=139 \mathrm{~mm} \div 246 \mathrm{~mm}$, 
- length of pick's working part: $L_{r}=50 \mathrm{~mm} \div 100 \mathrm{~mm}$ (correlated with length $L_{c}$ ),

- diameter of pick's shank part: one-stage: $d_{u}=\phi 30 \mathrm{~mm}, \phi 35 \mathrm{~mm}, \phi 38 \mathrm{~mm}$, two-stage: $\phi$ 30/38 mm,

- diameter of pick's flange: $\mathrm{d}_{\mathrm{k}}=\phi 48 \mathrm{~mm} \div \phi 7 \mathrm{~mm}$ (correlated with the diameter of the shank part),

- manner of pick mounting: circlip, HERT cotter pin, snap ring, friction ring,

- diameter of sintered carbide insert: $d_{w}=\phi 13 \mathrm{~mm} \div \phi 25 \mathrm{~mm}$,

- height of sintered carbide insert: $h_{w}=14 \mathrm{~mm} \div 40 \mathrm{~mm}$ (correlated with insert's diameter),

- tip angle: $2 \beta u=90^{\circ}, 93^{\circ}$, more than $100^{\circ}$ for the ballistic shape,

- shape of tip: conical, multi-conical, ballistic, hat-shaped,

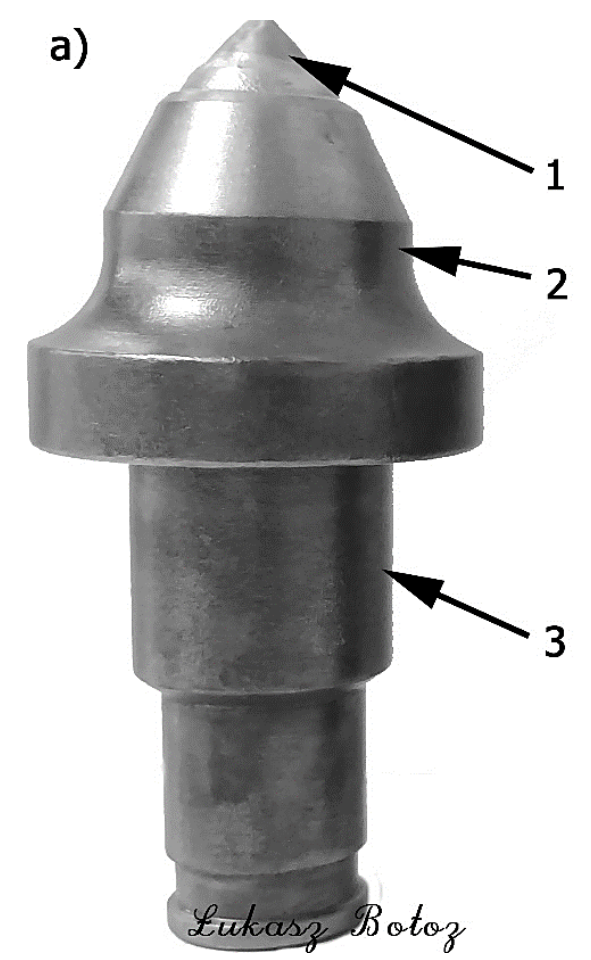

b)

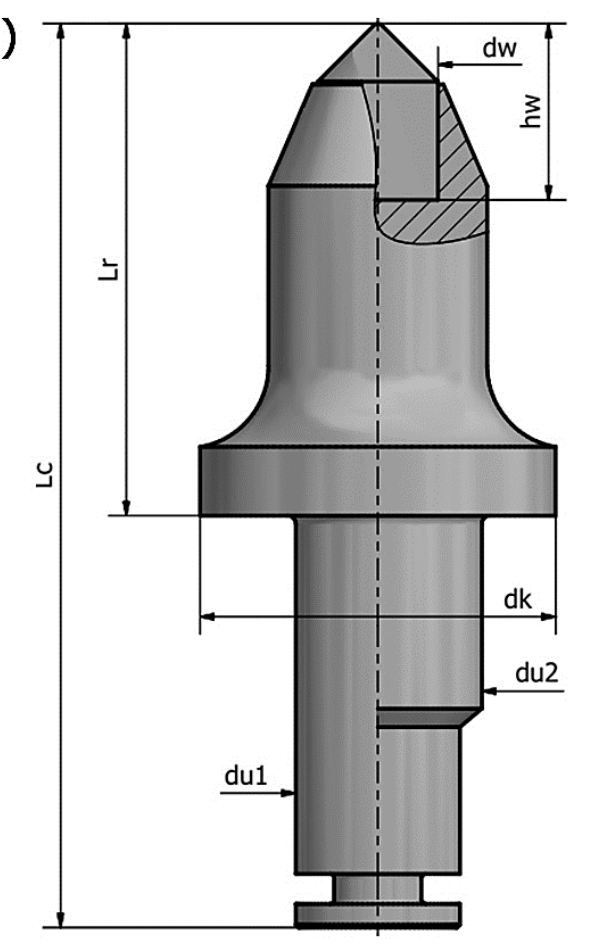

Fig. 1 Construction and basic dimensions of a conical pick

a) construction of the pick, b) basic dimensions of the pick

\section{INCREASINGTHE DURABILITY OF CONICAL PICKS}

The durability of properly working conical picks depends on the abrasive resistance of their tip and the working part of the body. The mining process frequently involves cutting abrasive rocks, which cause fast abrasive wear, especially of the steel body of the pick. For that reason, the basic direction for increasing the abrasive resistance of the pick's working part is applying a padding weld of sintered carbides or other abrasion resistant materials, rings made of sintered carbides or CAP carbides in picks with lowered bodies (Fig. 2). The presented methods are the most frequently applied in the case of abrasive rocks mining. Other available methods include among others:

- Application of synthetic diamond (polycrystalline diamond - PCD) on the pick's tip (Fig. 3a) - produced by US Synthetic Mining.

- Application of unique coatings (Fig. 3b) - produced by ARM CHINA Co., LTD. 
- Application of a body equipped with flat inserts made of sintered carbide (Fig. 3c) - produced by Wuhan Reetec Diamond Co., Ltd.

- Application of a body equipped with round inserts made of sintered carbide (Fig. 3d) - produced by Wuhan Reetec Diamond Co., Ltd.

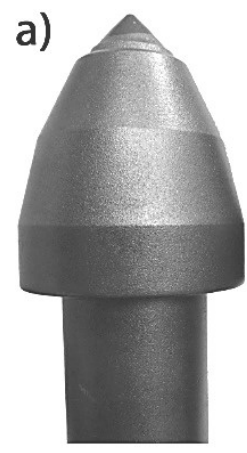

b)

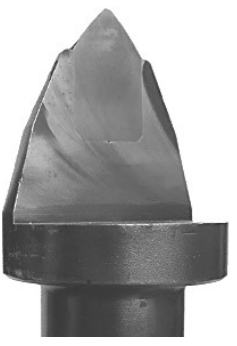

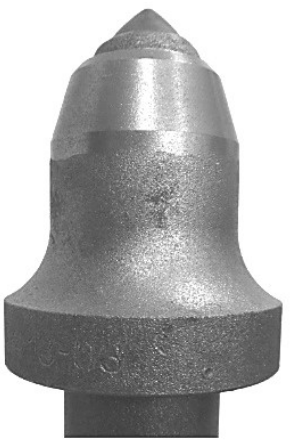

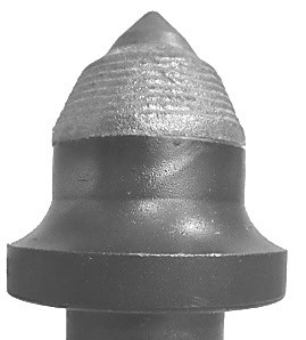

C)
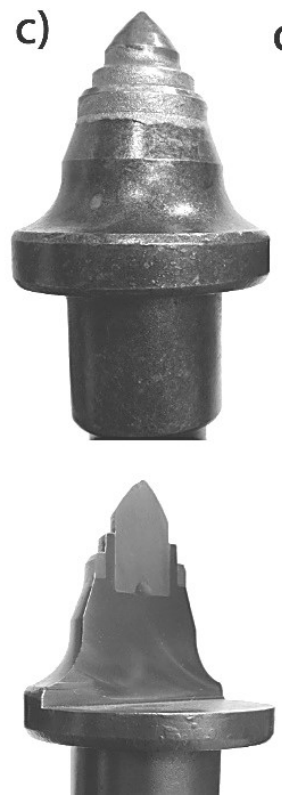

d)
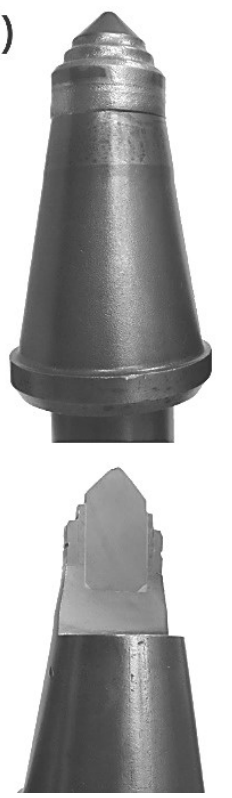

e)
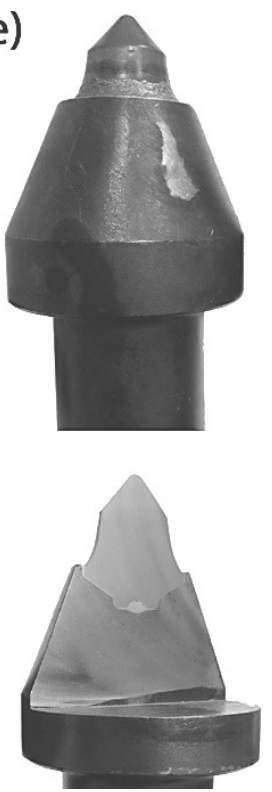

Fig. 2 Methods of increasing picks' durability

a) standard pick, b) hardfaced picks, c) pick with a ring made of sintered carbide, d) pick with two rings made of sintered carbide, e) pick with CAP carbide

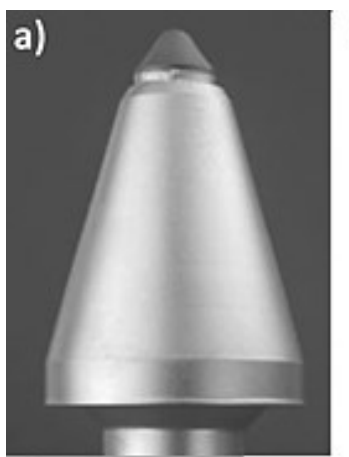

b)
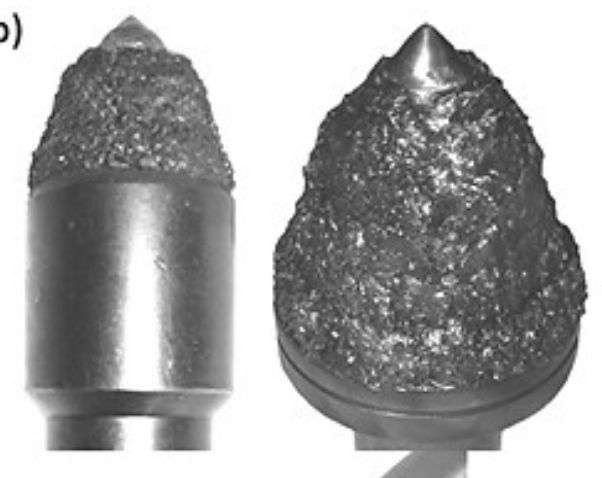

c)

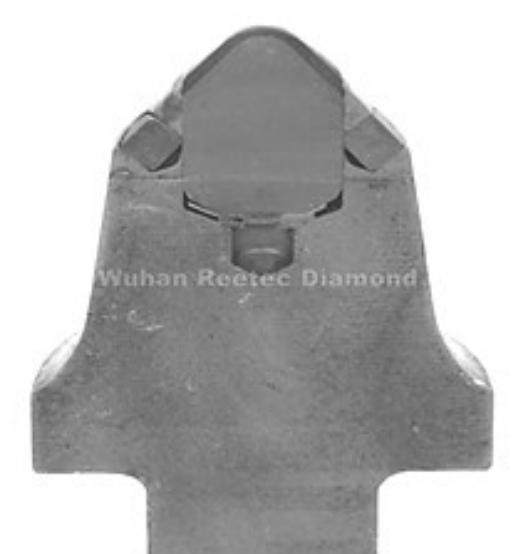

Fig. 3 Other methods of increasing the durability of conical picks

a) application of a tip made of PCD, b) application of unique coatings, c) application of a body equipped with flat inserts made of sintered carbide, d) application of a body equipped with round inserts made of sintered carbide 
Picks classified as used are changed for new ones. Picks after service are recycled, although they can also be regenerated. A well-known method of regenerating picks in the case of greater wear involves applying a replaceable working part together with the sintered carbide tip (Prokopenko et al., 2018). A used pick is subjected to treatment in order to make a seat for the tip adapter. Next, the adapter with a new tip of sintered carbide is mounted. In the opinion of the authors, it is possible to replace the tip several times, which results in a five-fold decrease in the metal wear and a reduction of costs.
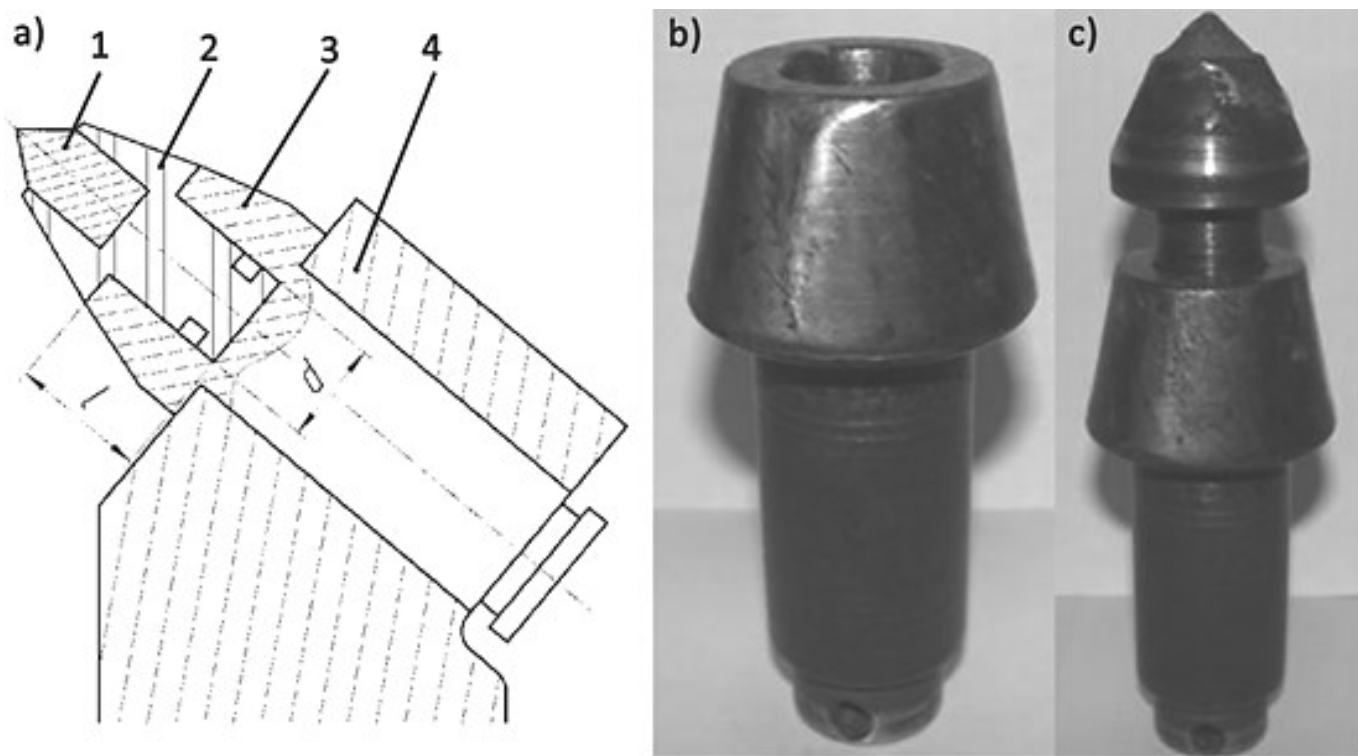

Fig. 4 Method of regenerating conical picks

a) method of regeneration: 1 - carbide tip, 2 - operating head, 3 - holding head, 4 - pick holder, b) pick body with a seat, c) pick with an adapter and a tip

\section{AUTHOR'S SOLUTION FOR THE CONICAL PICK HOLDER}

There are many solutions for conical pick holders, which in the process of milling must ensure the possibility of the pick's free and random rotation in relation to its axis. Rotation of the pick causes that its tip wears evenly and the shape is similar to the original one. The most common and, practically, the only applied solution is the holder with a cylindrical opening, in which the pick is mounted directly or by means of a sleeve. Dust penetrating into the unsealed area between the pick and the holder increases the rotational movement resistance, which causes its blocking and faster wear, necessitating the replacement. There are also solutions offering holders that have a more complex construction, with a rolling-element bearing of the pick and the bearing assembly sealing. Such solutions improve the mining conditions and increase the pick's durability. However, frequent pick replacements require this process to be fast and efficient, whereas application of bearing assemblies between the pick and the holder causes that they are exposed to dirt and damage. Additionally, both assembly and dismantling require care and precision, so these solutions are not currently applied. For this reason, a holder with a rolling-element bearing was developed. Thanks to its construction, pick replacement is simple and fast. At the same time, the possibility of contaminating the bearing seat has been 
eliminated. What is also important, in this solution, commercial conical picks are applied.

A characteristic feature of the holder in question is its bearing assembly, which has an additional neck bush. The bearing sleeve is placed on transverse needle roller bearings and on a longitudinal roller bearing. Both ends of the sleeve are equipped with seal rings. Additionally, the seal rings are secured against damage by steel guard rings. The sleeve opening has a shape and dimensions corresponding to those of commercial holders, which allows using standard conical picks. The holder ensures very little resistance of the pick's rotational movement. If a used pick has to be replaced for a new one, the time of replacement is shorter. When the used pick is being removed and the new one inserted, the bearing assembly remains tightly closed, preventing any contamination from getting in.

The concept of this solution has been presented in Fig. 5.

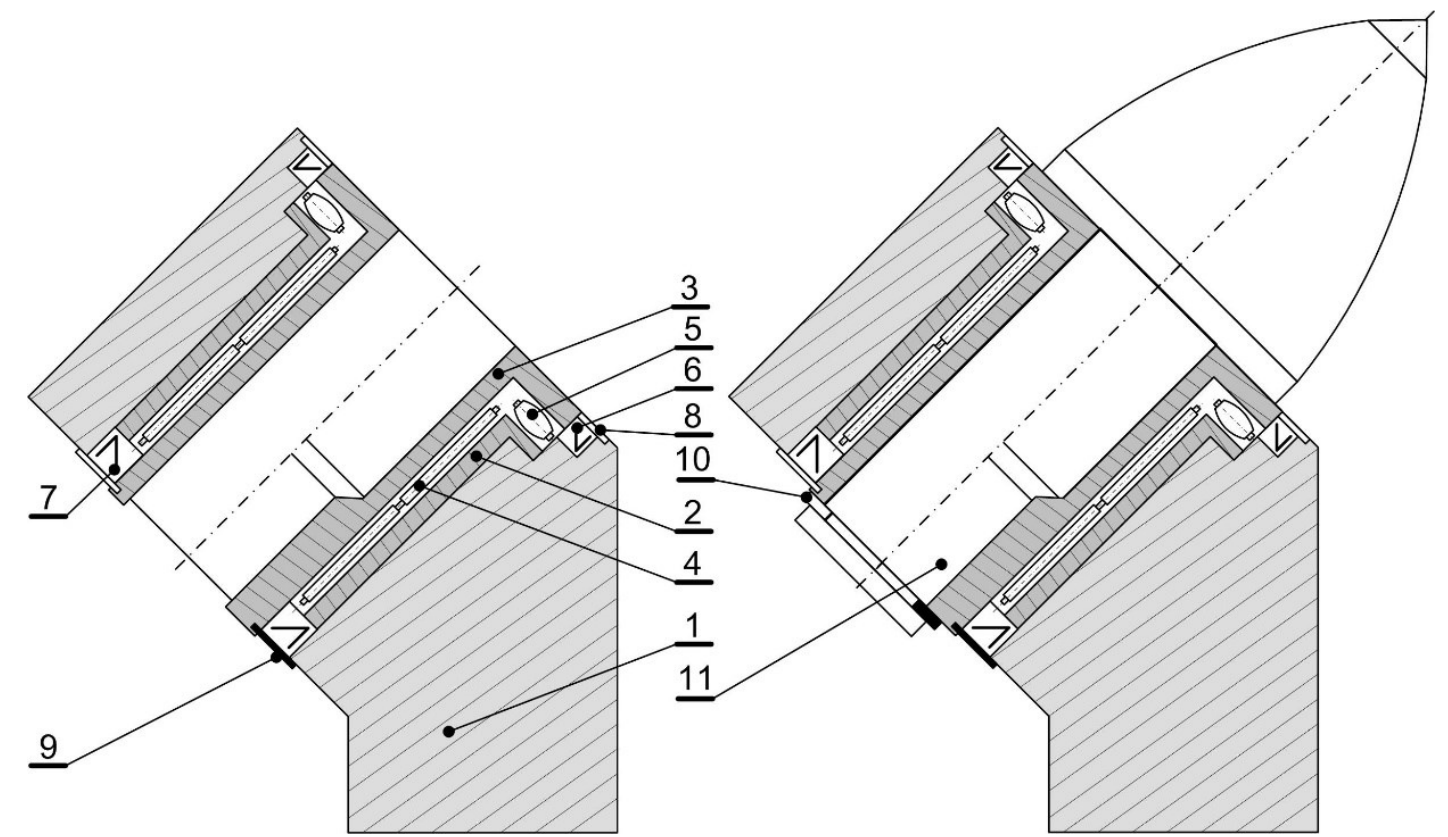

Fig. 5 Bearing-equipped holder of the conical pick (description is contained in the text)

The shape and size of the holder are compatible with the currently applied commercial solutions. In the body of holder 1 there is an immobile external neck bush 2 . In sleeve 2, an external raceway of the transverse needle roller bearing has been made. The internal raceway for needle roller bearing 4 is the external surface of internal neck bush 3. Commercial conical pick 11 is mounted by means of circlip 10. Between sleeves 2 and 3 , there is also a longitudinal roller bearing -5 . Both ends of sleeve 3 are equipped with seal rings - upper 6 and lower 7 . From the outside, seal rings 6 and 7 are covered by flat guard rings 8 and 9.

The author submitted an application for patent protection of the presented solution entitled "Conical pick holder mounted on the cutting head" No. P-428 397 on 27.12.2018. 


\section{AUTHOR'S SOLUTION FOR THE CONICAL PICK}

In difficult working conditions due to the presence of abrasive rocks, the pick in the holder is frequently blocked, which causes its fast and catastrophic wear, entailing the necessity of its immediate replacement. A solution to this problem might be the presented above holder. However, a properly working pick wears evenly, the length of its working part decreases while the shape is similar to that of a brand-new pick. The operational practice shows that in many cases the cause of pick's wear is not the wear of the tip made of sintered carbide, but the wear of the steel body. As a result, the unused tip gets crumbled or broken, and the pick needs to be replaced. The previously presented procedures allow the durability of the pick to be increased, in particular by protecting its working part. After analysing both the construction and the form of conical picks' wear, a new solution for the conical pick was developed. The solution involves making the pick's tip in a shape similar to the worn working part of the pick. The tip having a special shape can be made of sintered carbide or another abrasion resistant material. The tip can also consist of two permanently connected elements. The tip can be mounted in a standard way through brazing, or, separately, by means of a spring ring. Separate mounting enables fast replacement of the tip alone, without removing the pick. Moreover, application of a mobile connection between the tip and the pick by means of a slide bearing can be considered. The concept of this solution has been presented in Fig. 6 .

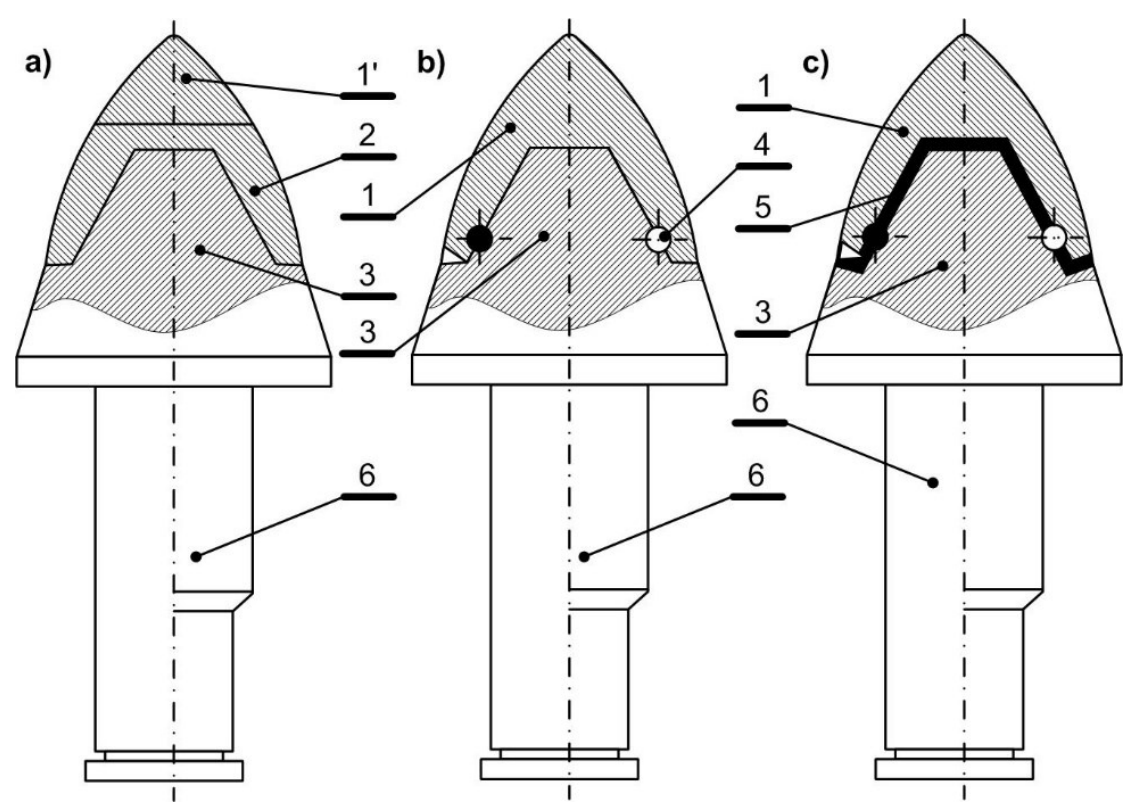

Fig. 6 Conical pick with a specially constructed tip (description is contained in the text) a) brazed tip, b) separately mounted tip c) tip with a slide bearing

The working part is equipped with one- (1) or two-part tip (1', 2) on the top. The two-part structure enables using two different materials, for example PCD for element 1' and sintered carbide for element 2. The tip is fixed to the pick's centering element 2. The shape of element 2 resembles that of the used pick. As a result, it is only the tip that is subject to wear, not the steel body of the pick. The tip can be connected in a standard way, in the process of brazing (Fig. 6a). 
Alternatively, the tip can be connected separately by means of spring ring 3 (Fig. $6 \mathrm{~b})$. Between the tip and the body of the pick, slide bearing 4 can be applied (Fig. $6 \mathrm{c}$ ). The pic has typical body 6 .

The author submitted an application for patent protection of the above presented solution entitled "Conical pick of the head for milling closely packed rocks" No. P-428 184 on 14.12.2018.

\section{CONCLUSIONS}

The milling of rocks with conical picks, especially in difficult and demanding conditions, results in their faster wear and necessary replacement. During work, conical picks are in direct contact with the excavated face, so their abrasive wear is unavoidable. Currently the most popular direction for conical picks' development is using modern abrasive resistant grades of steel for the body and sintered carbides for the tip. As the pick's working part is the most exposed to wear, coatings or rings that considerably increase durability are applied. As shown in the conducted analysis of the existing solutions, there are various methods and technical solutions for both the holder and the pick, which allow their working time to be extended. One of the ways is to apply holders equipped with bearings. The above described two solutions for the holder and the pick that have been proposed as directions for development are worth considering, as they allow the durability of picks to be increased. Both solutions are technically feasible. The industrial version of the bearing-equipped holder requires prototype testing, whereas the solution for the conical pick can be implemented without a research phase.

\section{ACKNOWLEDGEMENT}

The works were carried out under the dean's grant, contract 16.16.130.942.

\section{REFERENCES}

Bołoz $Ł$, Krauze K. (2018). Ability to mill rocks in open-pit mining. In: $18^{\text {th }}$ International Multidisciplinary Scientific Geoconference, Exploration and Mining, SGEM2018, Albena, Bulgaria, Voulme 2, pp. 41-48.

Bołoz Ł. (2018). „Results of a study on the quality of conical picks for public procurement purposes", in Proceedings of the international conference on Human safety in work environment: operating machinery and equipment: Integrated Management Systems: Quality - Environment - Safety, 23-27 october 2018, GdańskNynashamn-Sztokholm-Tallin-Sztokholm-Nynashamn-Gdańsk, pp. 687-693.

Chang S., Lee, Chulho, Kang. (2017). Tae-HoEffect of hardfacing on wear reduction of pick cutters under mixed rock conditions. Geomechanics and engineering, 13(1), pp. 141-159.

Dewangan, Saurabh, Chattopadhyaya, Somnath, (2015). Critical Analysis of Wear Mechanisms in Cemented Carbide. Jorunal of materials engineering and performance, 24(7), pp. 2628-2636.

Gajewski J., Jedlinski L., Jonak J. (2013). Classification of wear level of mining tools with the use of fuzzy neural Network. Tunnelling and underground space technology, 35, pp. 30-36.

Gospodarczyk P, Kotwica K., Mendyka P., Stopka G. (2016). Innovative roadheader mining head with assymetrical disc tools, Exploration and mining, mineral 
processing. International Multidisciplinary Scientific GeoConference SGEM, Sofia, 2, pp. 489-496.

Gospodarczyk P., Kotwica K., Stopka G. (2013). A new generation mining head with disc tool of complex trajectory, Archives of Mining Sciences, 58(4), pp. 985-1006.

Kotwica K. (2011). The influence of water assistance on the character and degree of wear of cutting tools applied in roadheaders. Archives of Mining Sciences, 5(3), pp. 353-374.

Kotwica K. (2018). Atypical and innovative tool, holder and mining head designed for roadheaders used to tunnel and gallery drilling in hard rock. Tunnelling and Underground Space Technology, 82, pp. 493-503.

Krauze K., Bołoz Ł. (2018). Disc unit dedicated to mine abrasive rocks and in particular copper ores. In: 18th International Multidisciplinary Scientific Geoconference, Exploration and Mining, SGEM2018, Albena, Bulgaria, Voulme 2.

Krauze K., Bołoz Ł., Wydro T. (2015). Parametric factors for the tangential-rotary picks quality assessment, Archives of Mining Sciences, 60(1), pp. 265-281.

Nahak, Sakuntala; Dewangan, Saurabh; Chattopadhyaya, Somnath. (2015). Discussion on Wear Phenomena in Cemented Carbide. In: Global Challenges, Policy Framework \& Sustainable Development for Mining of Mineral and Fossil Energy Resources. Dhanbad: GCPF, 11, pp. 284-293.

Prokopenko S. A., Vorobiev A. V., Lyudmila A., Janocko J. (2018). Waste Cutters Utilization in Underground Coal Mining, Acta Montanistica Slovaca, 23(1), pp. 8189.

Romanyshyn T., Dzhus A., Romanyshyn L. (2017). Design and research of fishing tools with national parameters of magnetic systems. Eastern-European Journal of Enterprise Technologies, 88(4/5), pp. 17-22.

Songyong L., Huifu; J., Xiaohui L. (2017). Experimental research on wear of conical pick interacting with coal-rock. Engineering failure analysis, 74, pp. 172-187.

Gajdzik B., Sitko J. (2014). An analysis of the causes of complaints about steel sheets in metallurgical product quality management systems. Metalurgija, 53(1), pp. 135138.

Gajdzik B., Sitko J. (2016). Steel mill products analysis using qualities methods, Metalurgija, 55(4), pp. 807-810. 


\begin{abstract}
.
Conical picks are cutting tools used in many branches, in particular in the mining, road construction and building branch. Contact with the excavated face causes their constant wear, which is an unfavorable but unavoidable process. Milling heads of working machines are equipped with several dozen conical picks, and mining in abrasive or hardly accessible rocks can reduce their life to a few hours. It is in the interest of both users and producers to increase their durability, as tools replacement, apart from purchase and logistic costs, results in machine downtimes. In the article various solutions of conical picks, their construction, dimensions and materials used have been discussed. Technical procedures applied to increase the durability of conical picks and their regeneration as well as methods of extending the life of picks working in difficult conditions have been presented. Two author's methods of extending the life of picks working in difficult conditions, covered by a patent application, have also been presented. The first solution involves ensuring an uninterrupted rotational movement of the pick in the holder. Patent claims include an innovative method of equipping the additional sleeve integrated with the holder with a rotational bearing, which enables a continuous rotation of the pick. The tool equipped with a bearing generates much lower movement resistance than the standard mounting. The holder is designed to mount classic commercial picks. What is important, the pick replacement does not require interfering with the bearing assembly. The second solution concerns the manner of protecting the working part of the pick by means of a special element made of an abrasion resisting material. This element is the pick tip, the geometry of which varies from the commonly applied posts made of sintered carbide. In this solution, the tip has a shape corresponding to the form of conical pick's wear, which causes that its steel body does not wear. Moreover, there is a possibility of applying a mobile, rotational mounting of the tip to the body.
\end{abstract}

Keywords: conical picks, durability of tools, tool wear rate, pick equipped with a bearing, innovative solutions 